HOMENAGEM AO PROF. SEGISMUNDO SPINA 

Lingua e Lileratura, v. 15, n. 18, p. 7-11, 1990.

\section{DISCURSO DO PROF. SEGISMUNDO SPINA}

Agradeço as palavras muito afetuosas do Prof. Dino Preti; peço, entretanto, licença para discordar dos adjetivos empregados, porque os juízos de valor ali expressos não conferem com a qualificação do homenageado; agradeço também a presença amável e fraternal de colegas e amigos que até aqui vieram, movidos naturalmente por velhas afinidades pessoais. E altamente honrosa a maneira que a Universidade oferece de as suas unidades coroarem a nossa jubilação profissional. Peço licença, entretanto, para dizer que o elogio sempre me incomodou; e o elogio institucionalizado - como são as homenagens - me tirou o sono. Tive que ir-me acostumando paulatinamente com a idéia de receber esta outorga. Foi para mim uma surpresa muito grande, porque nunca suspeitei haver ultrapassado aquele conjunto de obrigações inerentes às tarefas da docência: honestidade intelectual, assiduidade, culto do espírito crítico e da pesquisa - qualidades que qualquer professor deve possuir. O único predicado talvez que transcendeu ou extrapolou esse conjunto de virtudes foi haver permanecido 42 anos trabalhando. Em termos de turmas que se formam, posso dizer que uma dezena de geraçōes passou pelo meu magistério, apenas nesta Escola. Muitos dos docentes que hoje militam na área de Letras - inclusive titulares - foram alunos meus. Alguns já se esqueceram disso, mas em compensação outros não se cansam de confessar o seu discipulato, às vezes numa forma de gratidão que comove. Devo ter despertado, por outro lado, inúmeras antipatias, tipo esquisito como sempre fui. Às vezes, chato. Em contrapartida aprendi muito nesta casa, desde o convívio com os colegas de bancos escolares, o convívio de funcionários, o convívio de meus mestres numa época em que os professores estrangeiros, por imperativos da II $^{\mathrm{a}}$ Grande Guerra, já abandonavam as suas cátedras e regressavam ao país de origem, deixando os novos discípulos que procuraram germinar as sementes aqui plantadas; aprendi com meus colegas de trabalho, e aprendi, durante 30 anos de convivência ininterrupta com os colegas de Congregação. Modelos de dignidade intelectual e profissional não nos faltaram, desde o Colégio Universitário, que funcionava junto à Faculdade, no prédio da Caetano de Campos. Lembro-me com saudades das aulas brilhantes de um Clóvis Leite Ribeiro, com sua fascinante cultura literária; lembro-me com enternecimento do Prof. Stevanoni - com sua admirável paixão pelos problemas dantescos; de um Francisco Isoldi, professor de grego, paleógrafo da Biblioteca do Vaticano, muito baixinho, que se servia de uma cadeira para transcrever na lousa os textos que devíamos traduzir. Já na Faculdade, com que des- 

18, p. 7-11, 1990.

lumbramento ouvíamos as preleções do Prof. Fidelino de Figueiredo, que deixou marcas profundas com o seu ensino de alto nível e um discipulato que não envergonhou o seu magistério; de um Mário Pereira de Sousa Lima, cuja integridade e saber eram o orgulho desta escola; de um Aluísio de Faria Coimbra, cujo entusiasmo pela cultura clássica, a elegância de suas atitudes e a posse de uma erudição sólida contagiavam os seus alunos; de um Eduardo de Oliveira França, que nas letras ministrava cursos de história grega e história romana, e cujas aulas, sempre bem preparadas e fundamentadas numa bibliografia altamente especializada, constituíam o encanto de todos nós: França estava, nesses anos de 1943 e 1944, iniciando o auge de sua docência; de um professor Antônio Soares Amora, o professor mais perfeito que já conheci do ponto de vista didático, a cujas aulas durante 24 anos eu assisti religiosamente - no afã de assimilar esse condão profissional. Nessa época éramos "assistentes" na acepção da palavra, porque assistíamos às preleções de nossos mestres. $\mathrm{E}$ de tantos outros. $\mathrm{Na}$ Congregação não posso deixar de lembrar outros paradigmas de hombridade, bom-senso e compostura - virtudes que infelizmente se foram rarefazendo com o correr dos tempos: de um Fernando de Azevedo, de um Mário Schemberg, de um Milton Rodrigues, de um João Cruz Costa, de um Ernesto Américo Senise, de um Lourival Gomes Machado, de um Eurípides Simões de Paula, de um Rui Galvão de Andrade Coelho, de um Florestan Fernandes, para citar apenas alguns dos mais antigos, nomes que procuraram consolidar os altos padrões e as normas ideais que a Faculdade ainda adolescente procurava impor-se.

Mas, a maior das minhas alegrias nesta Escola foi haver criado um grupo de trabalho, a partir de 1969, quando tive de assumir a regência da então Cadeira de Filologia e Língua Portuguesa com a aposentadoria do seu catedrático, grupo esse que chegou a ser dos maiores em nossa Universidade, isto é, em número de 25. Com eles pude realizar os meus programas de trabalho, porque os uniu sempre um profundo respeito mútuo e um permanente espírito de solidariedade. Foi uma verdadeira família, uma comunidade que viveu na mais completa harmonia, em que as raras idiossincrasias pessoais desapareciam em meio ao entusiasmo de trabalho que os caracterizava. Espero que esse grupo continue como eu deixei. Orgulho-me também de haver conseguido criar, em 1959, a Disciplina de Camonologia, da qual estive à testa até à minha aposentadoria com cursos de Pós-Graduação; e com ela haver criado uma revista, a Revista Camoniana, em 1964, ainda hoje com vida, já no $\mathrm{n}^{9} 7$ da sua $2^{\mathrm{a}}$ Série, única revista especializada no mundo a versar os problemas ligados ao Príncipe dos Poetas de Espanha.

Esta a história sumária das minhas alegrias na Faculdade, do que devo a ela e do que a ela deixei. Outros momentos de alegria não posso deixar de lembrar nesta rápida "hora da saudade": em 1949 fomos o primeiro professor a inaugurar os chamados "Cursos de extensão universitária", pelo interior do Estado, instituídos pela Reitoria, proferindo 4 palestras na cidade de Marília; em 1959 proferíamos também a $1^{2}$ Aula Inaugural na Faculdade de Filosofia, Ciências e 
SPINA, Segismundo. Discurso do Prof. Segismundo Spina. Língua e Literatura, v. 15, n. 18, p. 7-11, 1990.

Letras de Marília, ano de sua fundação. Em março de 1988 fomos convidados para a aula inaugural dos cursos de Letras, em razão de nossa interferência na construção do prédio de Letras, prometida pelo Reitor em carta que nos escreveu, assegurando que uma de suas primeiras gestões como Reitor seria a edificação de nosso prédio; e por ocasiāo de nossa aposentadoria, em 1986, escreveu-nos novamente o Prof. Goldemberg agradecendo os serviços prestados à Universidade e reiterando o seu interesse no término da construção, que ele previa para agosto de 1987.

Mas teriam, os que me ouvem, o direito de perguntar: com tanta experiência de vida na Universidade, que diriamos nós da instituiçāo universitária? - dos seus objetivos, dos seus acertos e dos seus desacertos, do seu significado e do seu papel na nossa sociedade? Não saberíamos responder. O meu acentuado pendor pela cultura desinteressada desde que transpus o umbral da Faculdade, talvez me tivesse suprimido esse dever de penetrar nos fundamentos da instituição universitária. Em mais de quatro décadas, lembro-me de haver participado apenas uma vez de uma assembléia, em que lutávamos pela autonomia dos cursos de Letras, e perdemos fragorosamente. Com que inveja leio os pronunciamentos de meus colegas - e foram tantos por ocasião da desventurada publicação da lista dos professores improdutivos, em que os valores mais argutos de nossa escola dissertaram sobre o papel das Universidades, distinguindo as suas funções de ensino e de pesquisa, e seus deveres com a comunidade. A recente reestruturaçăo dos Estatutos como viram - suscitou também os pronunciamentos mais relevantes a propósito da composição e do espírito da instituição - em crise nos seus alicerces, porque "o cavalo de Tróia do populismo invadiu a Universidade" - no dizer recente de Miguel Reale, e o conúbio com a instituição empresarial estiolou as mais legítimas finalidades da vida universitária.

Ao invés de abordar problemas que transcendem a nossa capacidade crítica, gostaríamos, se a paciência dos presentes nos permite, de fazer algumas confissões de ordem pessoal, anedóticas porque nunca foram publicadas, ou folclóricas porque todos nós temos fatos de importância puramente subjetiva mas significativos para relatar: como entrei na Faculdade e como comecei a trabalhar nela. Peço permissão para um excurso em primeira pessoa.

Terminando o Colégio Universitário em 1942, prestei vestibulares em fevereiro de 1943, tendo sido reprovado com nota zero no exame oral de Português, porque a nota 9 da Prova Escrita dava a média 4,5, insuficiente para a minha aprovação. Desiludido, aguardei no Viaduto do Chá, diante da Light, por onde sempre passava, o professor que acabara de me reprovar, a fim de com ele tirar satisfações, embora já decidido a voltar para o interior, para Lins, onde minha família residia e meu pai mantinha uma oficinazinha de sapateiro. Eu estava decidido a retornar à minha antiga vocação para o artesanato em couro, pois nos tempos em que cursava o ginásio praticava o meu ofício de seleiro. Infelizmente não tenho condições de documentar esse encontro com o professor que me classificara 
de "burro" e me desclassificara no vestibular, porque os dois colegas que lhe faziam companhia já faleceram: o Prof. Sousa Lima e o Prof. Manuel Cerqueira Leite; mas está com vida ainda a personagem central do enredo - que poderá atestar a veracidade do episódio. Abordado, discuti com ele o absurdo daquela decisão, e sua resposta não foi outra: "cresça e apareça. Vá estudar primeiro e volte quando estiver preparado". Além de reprovado, humilhado. Num assomo de orgulho ferido, respondi-lhe: "Pois bem: eu ainda vou ser catedrático na sua Faculdade!", ao que ele resondeu com uma gargalhada satânica: "Catedrático!".

Houve uma $2^{a}$ época dos vestibulares naquele ano; mas eu me encontrava de malas prontas, na chácara de uma família que me ajudara financeiramente nos estudos, em Catanduva, aguardando a hora do ónibus que me levaria para Lins, na Noroeste, quando um estafeta do Telégrafo me traz um telegrama, que me advertia da realização de um novo vestibular e que eu retornasse imediatamente para São Paulo. Estranho telegrama: era o primeiro telegrama que eu recebia em toda a minha vida. Por isso que sempre acreditei nos gregos - que explicavam os fatos circunstanciais da vida pela Tyché, mas a fatalidade pela Moira, isto é, pelo fatum: o nosso destino está escrito, e nem os deuses o podem modificar. Esse telegrama vinha assinado por Michel Pedro Sawaya, que em 1934, então professor primário em Itajobi, minha terra natal, era nosso hóspede e me havia preparado para o exame de admissão ao ginásio do Estado em Catanduva. Em 1935 Michel Pedro Sawaya, como normalista, podia ingressar, sem Colégio Universitário, na faculdade de Filosofia, Ciências e Letras, recentemente criada. Veio para São Paulo, conseguiu o seu intento, mas nunca mais o vi; e aqui terminou - como todos sabem - de forma invejável a sua vida profissional na Cadeira de Zoologia. Em Janeiro deste ano, o Prof. Michel infaustamente nos deixou. Vendo o meu nome na relação de reprovados, telegrafou-me para um endereço que a Secretaria de Colégio Universitário lhe fornecera. E o resultado desse telegrama: em novembro de 1969 o CTA da Faculdade me convidava para assumir a regência da Cadeira de Filologia e Língua Portuguesa; em 1973 fazia concurso para Titular nessa área; e só a Reforma da Universidade em 1969 me subtraiu a satisfação de cumprir a minha promessa: ser Catedrático - e, acima disso, na própria área em que fora reprovado, 30 anos antes, nos vestibulares. A Reforma havia extinguido as cátedras.

Um segundo excurso, já que a paciência dos que me ouvem conseguiu manter-se até aqui. Ingressado na Faculdade e realizado meu sonhado curso de Letras Clássicas, como foi que entrei para o quadro docente desta Escola?

1944. Em plena guerra. Cursava eu o $2^{\circ}$ ano da Graduação. Tudo era difícil: emprego, livros estrangeiros, especialmente de grego e de latim; em fins desse ano, por generosidade do Prof. André Dreyfus, então Diretor da Faculdade, fui admitido, como Monitor (figura que nem existia) junto à Cadeira de Literatura Portuguesa, apenas com o intuito de reforçar a minha subsisténcia, numa espécie de bolsa, pela qual passava a receber um pró-labore por serviços que na verdade 
n. 18, p. 7-11, 1990.

não eram prestados. Em 1945, retornando da Europa o Prof. Fidelino de Figuiredo e reassumindo a regência da Cadeira, achou muito estranha aquela situação; marcou um encontro para me conhecer. As minhas credenciais, para a consolidação de uma afeição profunda que acabou despertando entre nós até 1967 - ano de sua morte - foram apenas duas: o Prof. Fidelino se lembrara de que em fins de 1943 (estava no $1^{2}$ ano da Faculdade) me abraçara em plena sala de aula pela nota 10 que havia granjeado por um trabalho de aproveitamento em fim de curso, que muito pretensiosamente eu havia intitulado de "Os elementos clássicos no teatro popular vicentino"; e pelo fato de haver publicado naquela altura uma obra sobre Gregório de Matos, meu primeiro livro, sob a orientação do Prof. Soares Amora, que dirigia uma linha de publicação intitulada "Pequena Biblioteca de Literatura Brasileira" para a Editora Assunção. E com estas credenciais, miseráveis, na verdade, o Prof. Fidelino me pôs a trabalhar, na condição de professor, antes de terminar a Graduação. E o que foi honroso para mim: o Prof. Fidelino passou a assistir às minhas aulas. E assim decorreram 28 anos de docência e convívio na Disciplina de Literatura Portuguesa, quando em 1973 prestava concurso para a área de Filologia e Língua Portuguesa - no cumprimento da minha pretensiosa profecia de 1943.

E hoje, quando imaginava estar apenas no gozo de um recesso, sou surpreendido pelos ventos da sorte, para vir receber neste instante um título desta natureza, que deve ser mais um testemunho de afeição das amizades que nesta Escola plantei e cultivei, do que propriamente reconhecimento inquestionavelmente merecido.

Saio daqui, a partir deste momento, completamente realizado. Vivi para a Universidade, não da Universidade; porém, no cômputo das coisas, se pesarmos aquilo que a ela dediquei e aquilo que dela recebi, estou convencido de que a Universidade ainda sai perdendo.

Muito obrigado.

Segismundo Spina. 